\title{
Preparation and properties of poly(acrylic acid) oligomer stabilized superparamagnetic ferrofluid
}

\author{
Chia-Lung Lin, Chia-Fen Lee ${ }^{1}$, Wen-Yen Chiu * \\ Department of Materials Science and Engineering, National Taiwan University, Taipei, Taiwan, Republic of China
}

Received 20 February 2005; accepted 9 May 2005

Available online 11 July 2005

\begin{abstract}
Ferrofluids, which are stable dispersions of magnetic particles, behave as liquids that have strong magnetic properties. Nanoparticles of magnetite with a mean diameter of $10-15 \mathrm{~nm}$, which are in the range of superparamagnetism, are usually prepared by the traditional method of co-precipitation from ferrous and ferric electrolyte solution. When diluted, the ferrofluid dispersions are not stable if anionic or cationic surfactants are used as the stabilizer. This work presents an efficient way to prepare a stable aqueous nanomagnetite dispersion. A stable ferrofluid containing $\mathrm{Fe}_{3} \mathrm{O}_{4}$ nanoparticles was synthesized via co-precipitation in the presence of poly(acrylic acid) oligomer. The mechanism, microstructure, and properties of the ferrofluid were investigated. The results indicate that the PAA oligomers promoted the nucleation and inhibited the growth of the magnetic iron oxide, and the average diameter of each individual $\mathrm{Fe}_{3} \mathrm{O}_{4}$ particle was smaller than $10 \mathrm{~nm}$. In addition, the PAA oligomers provided both electrostatic and steric repulsion against particle aggregation, and the stability of dispersions could be controlled by adjusting the $\mathrm{pH}$ value of solution. A small amount of $\mathrm{Fe}_{2} \mathrm{O}_{3}$ was found in the nanoparticles but the superparamagnetic behavior of the nanoparticles was not affected.
\end{abstract}

(C) 2005 Elsevier Inc. All rights reserved.

Keywords: $\mathrm{Fe}_{3} \mathrm{O}_{4}$; Poly(acrylic acid); Ferrofluid; Superparamagnetic; Nanoparticles

\section{Introduction}

Ferrofluids are colloidal dispersions of small singledomain magnetic particles suspended in a carrier fluid. Ferrofluids characteristically have both magnetic and fluid properties and have found a diverse range of applications, such as in audio devices, inertia dampers, stepper motors, sensors, vacuum seals, electromagnetic shielding, and highdensity digital storage $[1,2]$. In general, finer particles are more surface active; i.e., they have a higher specific surface area. On the other hand, it is often difficult to handle fine particles such as colloids. For example, the filtration will be time-consuming or impractical, or else a centrifuge has to be used. But unlike other ultrafine particles, mag-

\footnotetext{
* Corresponding author. Fax: +886223623259.

E-mail address: ycchiu@ccms.ntu.edu.tw (W.-Y. Chiu).

1 Present address: Department of Cosmetic Science, Chia Nan University of Pharmacy and Science, Tainan, Taiwan, Republic of China.
}

netic particles can be handled by an external magnetic field. Therefore, ferrofluids are widely studied for their applications in various fields in biology and medicine such as enzyme and protein immobilization, genes, radiopharmaceuticals, magnetic resonance imaging MRI, diagnostics, immunoassays, purification, separation, and controlled drug release [3-6]. However, the nanoparticles in the ferrofluids are likely to aggregate. Consequently, how to prevent aggregation between the nanoparticles during synthesis and treatment has received considerable attention when the applications need well-dispersed magnetic nanoparticles. Although well-dispersed magnetic nanoparticles can be obtained by ball milling [7], high-energy requirements and unavoidable contamination of the product have necessitated the development of more economical and reliable ways to produce magnetic particles by chemical coprecipitation.

Iron oxide $\left(\mathrm{Fe}_{3} \mathrm{O}_{4}\right)$, the dominant magnetic material in magnetic fluid preparations, can be synthesized through the coprecipitation of $\mathrm{Fe}(\mathrm{II})$ and $\mathrm{Fe}(\mathrm{III})$ salts by addition of a 
base. Stable ferrofluids can be prepared by adsorption of stabilizing agents on the surface of magnetite particles after a synthesis process. The feasibility of preparing magnetic fluids using anionic or nonionic surfactants as dispersing agents has been examined [8-10]. Massart obtained stable aqueous alkaline and acidic magnetic liquids by free precipitation $[11,12]$. The nature of the counterions and the $\mathrm{pH}$ of the suspensions played an important role in stabilizing the charged magnetic particles through interactions between their electrical double layers. The applications of magnetic fluids, which are stabilized entirely by electrostatic repulsion, are somewhat restricted, since this system is overly sensitive to conditions such as $\mathrm{pH}$ and ionic strength and offers little flexibility for changing the surface properties of the particles. Stabilization of magnetic fluid suspensions can be achieved by coating the particle surfaces with organic surfactants. When two such particles approach each other, the surfactants interpenetrate and the particles are subjected to steric repulsion due to an increase in osmotic pressure $[8,13]$.

The traditional methods of preparing ferrofluids involve long-term grinding of magnetic materials in a carrier medium containing oleic acid, which is commonly used as a dispersing agent to stabilize dispersions in kerosene and other hydrocarbon dispersion media. This method has prompted the application of the same technique to prepare a water-based magnetic fluid. The latter preparation was anticipated to be much simpler, since one usually starts with aqueous solutions of ferrous and ferric salts. Shimoiizaka et al. proposed the principle of bilayer stabilization in the early 1980s [14]. They first precipitated oleic acid-coated particles and then redispersed them in aqueous solutions of sodium dodecylbenzene sulfonate, poly(oxyethylene) nonylphenyl ethers, and di(2-ethylhexyl)adipate. The colloidal particles are thus doubly coated, first with a chemisorbed monolayer of oleic acid on top of which a second layer of the surfactant is physically adsorbed. Following this work, Khalafalla and Reimers [7] and Wooding et al. [15] produced stable aqueous magnetic fluids using various saturated and unsaturated fatty acids as primary and secondary surfactants. In our previous studies [16,17], we have also synthesized ferrofluids by adsorbing stabilizing agents, lauric acid, after the co-precipitation process [7,16-18]. However, the ferrofluids thus prepared were not stable when being diluted. Aggregation of particles occurred when excess quantity of water was added. Applications of magnetite dispersions composed of electrostatic stabilizers and bilayer surfactants are restricted due to $\mathrm{pH}$ sensitivity and dispersion stability, respectively [7].

Recently, aqueous magnetic fluids have been reported using polymers as steric stabilizers and polymer templates [19-24]. But it should be noted that many of the reported polymeric stabilizers have not been designed with functional groups to bind to the surface of $\mathrm{Fe}_{3} \mathrm{O}_{4}$ particles, and thus, stability of ferrofluid has been limited [24]. This study presents a novel and simple procedure to synthesize an extremely stable and water-based $\mathrm{Fe}_{3} \mathrm{O}_{4}$ ferrofluid via a co- precipitation method in the presence of poly(acrylic acid) oligomers. The PAA oligomers were chemically bound on the surface of $\mathrm{Fe}_{3} \mathrm{O}_{4}$ nanoparticles to suspend the $\mathrm{Fe}_{3} \mathrm{O}_{4}$ particles in a fine state of dispersion, and the PAA oligomers provided both electrostatic and steric repulsion against particle aggregation.

\section{Experimental}

\subsection{Materials}

$\mathrm{Fe}(\mathrm{II})$ chloride tetrahydrate (99\%), $\mathrm{Fe}(\mathrm{III})$ chloride hexahydrate $(97 \%)$, and ammonium hydroxide $\left(28 \% \mathrm{NH}_{3}\right.$ in water, w/w) were purchased from ACROS and used as supplied. Poly(acrylic acid) (PAA oligomer: $M_{\mathrm{W}} \sim 2000$ ) was purchased from Aldrich. Other chemicals were of analytical grade and used without further purification. Distilled and deionized water was used throughout the work.

\subsection{Synthesis of ferrofluid}

The stable $\mathrm{Fe}_{3} \mathrm{O}_{4}$ ferrofluid was synthesized using the method of coprecipitation of $\mathrm{Fe}(\mathrm{II})$ and $\mathrm{Fe}(\mathrm{III})$ salts in the presence of PAA oligomer $\left(M_{\mathrm{W}} \sim 2000\right)$. In this process, $1 \mathrm{~g}$ of PAA oligomer $\left(M_{\mathrm{w}} \sim 2000\right), 4.75 \mathrm{~g}$ of $\mathrm{FeCl}_{3} \cdot 6 \mathrm{H}_{2} \mathrm{O}$, and $1.75 \mathrm{~g}$ of $\mathrm{FeCl}_{2} \cdot 4 \mathrm{H}_{2} \mathrm{O}$ were dissolved in $80 \mathrm{ml}$ of water with vigorous stirring at $60^{\circ} \mathrm{C}$ under $\mathrm{N}_{2}$. Then $7.5 \mathrm{ml}$ of $\mathrm{NH}_{4} \mathrm{OH}(28 \%(\mathrm{w} / \mathrm{w}))$ was quickly added to the reactor and stirring was continued at $400 \mathrm{rpm}$ for $30 \mathrm{~min}$. Once the ammonium solution was added into the reactor, the color of the mixture turned from orange to black immediately. The ferrofluid thus obtained was designed by the sample code of PAA/MAG $=1 / 2$, in which the weight ratio of PAA oligomers to $\mathrm{Fe}_{3} \mathrm{O}_{4}$ particles was theoretically calculated as $1 / 2$ from the feed composition.

\subsection{Observation of $\mathrm{Fe}_{3} \mathrm{O}_{4}$ nanoparticles}

To observe the morphology of PAA oligomer-stabilized $\mathrm{Fe}_{3} \mathrm{O}_{4}$ particles, the ferrofluid was diluted in deionized water and observed by using a TEOL JSM-1200 EX II transmission electron microscope (TEM). In addition, the ferrofluid was coated on a glass plate and dried naturally, and then was observed by using a Hitachi S-800 scanning electron microscope (SEM).

\subsection{Measurement of FTIR}

To prepare the samples for the FTIR measurements (BioRad FTS-3000 spectrometer), the PAA oligomers which were used as supplied were grind-blended with $\mathrm{KBr}$ and then compressed to form a pellet. In addition, the ferrofluid was dialyzed (molecular weight cut off MWCO $=6000$ 8000 ) against deionic water until the conductivity of the solution was stable and then was freeze-dried to form the PAA 
oligomers stabilized $\mathrm{Fe}_{3} \mathrm{O}_{4}$ particles. In the same way, the sample of PAA oligomers stabilized $\mathrm{Fe}_{3} \mathrm{O}_{4}$ particles were grind-blended with $\mathrm{KBr}$ and then compressed to form a pellet for the measurement of FTIR. The transmission spectra were obtained for 64 scans at a resolution of $4 \mathrm{~cm}^{-1}$.

\subsection{Measurement of particle size distribution and zeta potential of $\mathrm{Fe}_{3} \mathrm{O}_{4}$ nanoparticles}

The zeta potential and the size distribution of the PAA oligomers stabilized $\mathrm{Fe}_{3} \mathrm{O}_{4}$ particles were measured by using laser light scattering (Malvern Zeta Sizer $3000 \mathrm{H}$ ) at $25^{\circ} \mathrm{C}$. Before the measurements, the ferrofluids were dialyzed for 7 days and diluted with distilled and deionized water.

\subsection{Stability of ferrofluid}

To investigate the effect of $\mathrm{pH}$ value on the stability of ferrofluid, the $\mathrm{pH}$ value of the ferrofluid was measured during the process of titration using $28 \%(\mathrm{w} / \mathrm{w})$ ammonium solution as a titrant. When the $\mathrm{pH}$ value of solution was stable for several minutes, the stability of the particles suspended in the fluid was observed visually. Furthermore, the effect of acid medium on the stability of the PAA oligomers stabilized $\mathrm{Fe}_{3} \mathrm{O}_{4}$ particles was studied by using methacrylic acid as a titrant to titrate the ferrofluid, which contained $2 \mathrm{ml} 28 \%$ (w/w) ammonium solution, and the $\mathrm{pH}$ value and stability of the $\mathrm{Fe}_{3} \mathrm{O}_{4}$ particles during the process of titration were observed.

\subsection{TGA and XRD analysis}

The ferrofluid was dialyzed until the conductivity of the solution was stable. Then the ferrofluid was freeze-dried to produce the PAA oligomer-stabilized $\mathrm{Fe}_{3} \mathrm{O}_{4}$ particles. The $\mathrm{Fe}_{3} \mathrm{O}_{4}$ particles were subjected to TGA (Perkin-Elmer TGA-7). The temperature was kept at $100^{\circ} \mathrm{C}$ for $10 \mathrm{~min}$ and then was raised to $800^{\circ} \mathrm{C}$ at a heating rate of $10^{\circ} \mathrm{C} / \mathrm{min}$. Additionally, X-ray diffraction measurements with monochromatic $\mathrm{Cu} K_{\alpha}$ radiation were taken to investigate the crystal structure of the particles.

\subsection{Measurement of magnetization of $\mathrm{Fe}_{3} \mathrm{O}_{4}$ particles}

The magnetization of the PAA oligomer-stabilized nanoparticles were measured by SQUID magnetometer (superconducting quantum interface device, Quantum Design MPMS5) at $298 \mathrm{~K}$ and $\pm 10,000 \mathrm{G}$ applied magnetic field. Due to the applied magnetic field $(H)$, the magnetic induction $(B)$ could be measured according to Faraday's law, and the magnetization $(M)$ was then obtained by the relationship

$$
B=H+4 \pi M .
$$

The applied magnetic field was increased until the saturation magnetization was achieved. Then the applied field was reduced to zero to measure the remanence (residual magnetization). When the applied field was further reversed, the coercivity (the applied field that reduces magnetization to zero) and the saturation magnetization in the reverse direction could be obtained. This increasing and decreasing applied field process was repeated five times to get the magnetization curve (magnetization $(M)$ versus applied magnetic field $(H)$ ) and examine the magnetic properties of the $\mathrm{Fe}_{3} \mathrm{O}_{4}$ particles.

In addition, the important parameters used to characterize the magnetic properties of solids, magnetic susceptibility $(\kappa)$, and magnetic permeability $(\mu)$ were also calculated using the following equations:

$$
\begin{aligned}
& \kappa=M / H, \\
& \mu=B / M .
\end{aligned}
$$

\section{Results and discussion}

\subsection{Synthesis of ferrofluid}

The traditional method of preparing $\mathrm{Fe}_{3} \mathrm{O}_{4}$ nanoparticles was to use the chemical co-precipitation of ferric and ferrous salts in alkaline medium:

$$
\begin{aligned}
\mathrm{Fe}^{2+}+2 \mathrm{Fe}^{3+}+8 \mathrm{OH}^{-} & \rightleftarrows \mathrm{Fe}(\mathrm{OH})_{2}+2 \mathrm{Fe}(\mathrm{OH})_{3} \\
& \rightarrow \mathrm{Fe}_{3} \mathrm{O}_{4}+\mathrm{H}_{2} \mathrm{O} .
\end{aligned}
$$

However, the $\mathrm{Fe}_{3} \mathrm{O}_{4}$ nanoparticles synthesized by this traditional method would aggregate easily, as shown in Fig. 1a. To prevent aggregation, the PAA oligomers were used to modify the traditional chemical co-precipitation method to synthesize the stable superparamagnetic ferrofluid. The ferrofluid containing the $\mathrm{Fe}_{3} \mathrm{O}_{4}$ nanoparticles could be suspended homogeneously and stably in water or monomer solution as shown in Fig. 1b. The proposed mechanism was shown in Fig. 2.

At first the $\mathrm{Fe}^{2+}$ and $\mathrm{Fe}^{3+}$ ions and the carboxylic acid groups of PAA oligomers formed a complex structure. After the ammonium solution was added, carboxylic acid groups on the PAA oligomer promoted the nucleation of $\mathrm{Fe}_{3} \mathrm{O}_{4}$ particles. Because the PAA oligomers acted as the template for $\mathrm{Fe}_{3} \mathrm{O}_{4}$ nucleation, the growth of particles would be hindered by the oligomers $[25,26]$ and the size of the particles was about 5-10 nm, which was smaller than the traditional product. Also, a lot of carboxylic acid groups were bound on the surface of $\mathrm{Fe}_{3} \mathrm{O}_{4}$ nanoparticles to suspend the particles in a fine state of dispersion as discussed later. The $\mathrm{Fe}_{3} \mathrm{O}_{4}$ nanoparticles could be synthesized in situ and form a hyperbranch structure as shown in Figs. 3a and 3b. But there is no evidence to explain the formation of a hyperbranch structure.

From the chemical equation of $\mathrm{Fe}_{3} \mathrm{O}_{4}$ precipitation, Eq. (4), the suitable mole concentration ratio of $\mathrm{Fe}$ (II) to $\mathrm{Fe}$ (III) should be $1 / 2$ for the synthesis of $\mathrm{Fe}_{3} \mathrm{O}_{4}$ nanoparticles. In addition, the suitable $\mathrm{pH}$ value for the synthesis of $\mathrm{Fe}_{3} \mathrm{O}_{4}$ nanoparticles should be higher than 6.93, which 

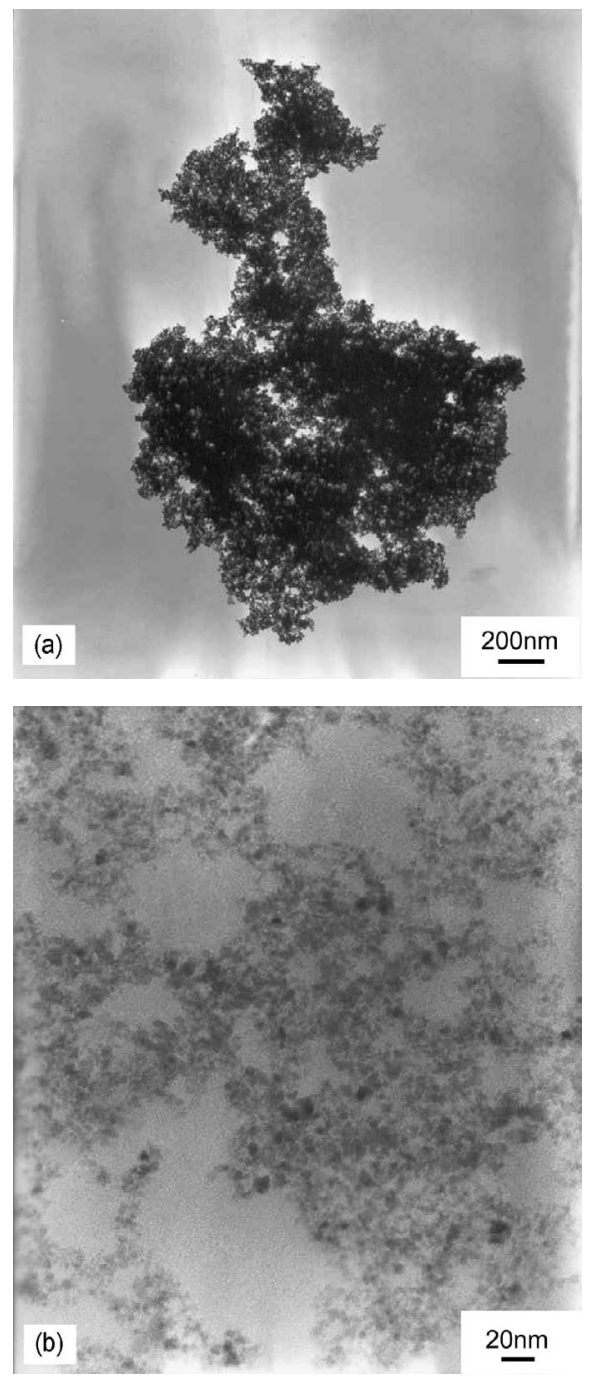

Fig. 1. TEM photographs of (a) $\mathrm{Fe}_{3} \mathrm{O}_{4}$ nanoparticles prepared by the method of co-precipitation in the absence of PAA oligomers; (b) ferrofluid prepared by the method of co-precipitation in the presence of PAA oligomers.
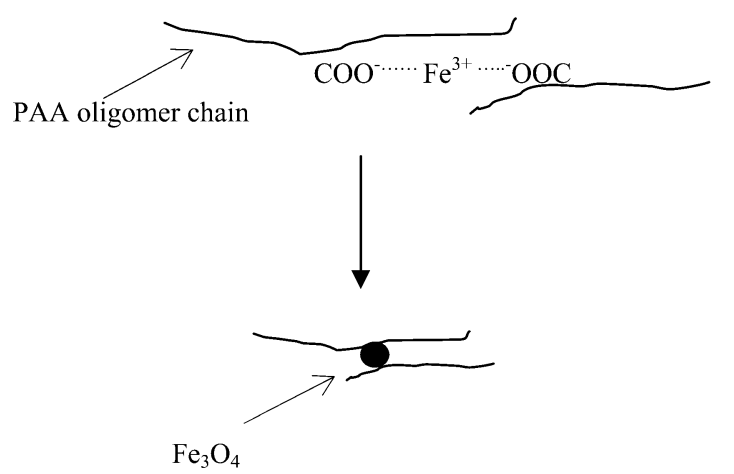

Fig. 2. Mechanism for the synthesis of ferrofluid: the nucleation of nanoparticles.

could be calculated using (4) for $K_{\text {sp }}$ values of $\mathrm{Fe}(\mathrm{OH})_{2}$ and $\mathrm{Fe}(\mathrm{OH})_{3}$ at $25^{\circ} \mathrm{C}$ of $8 \times 10^{-16}$ and $4 \times 10^{-38}$. If the mole concentration ratio of $\mathrm{Fe}$ (II) to $\mathrm{Fe}(\mathrm{III})$ was larger than
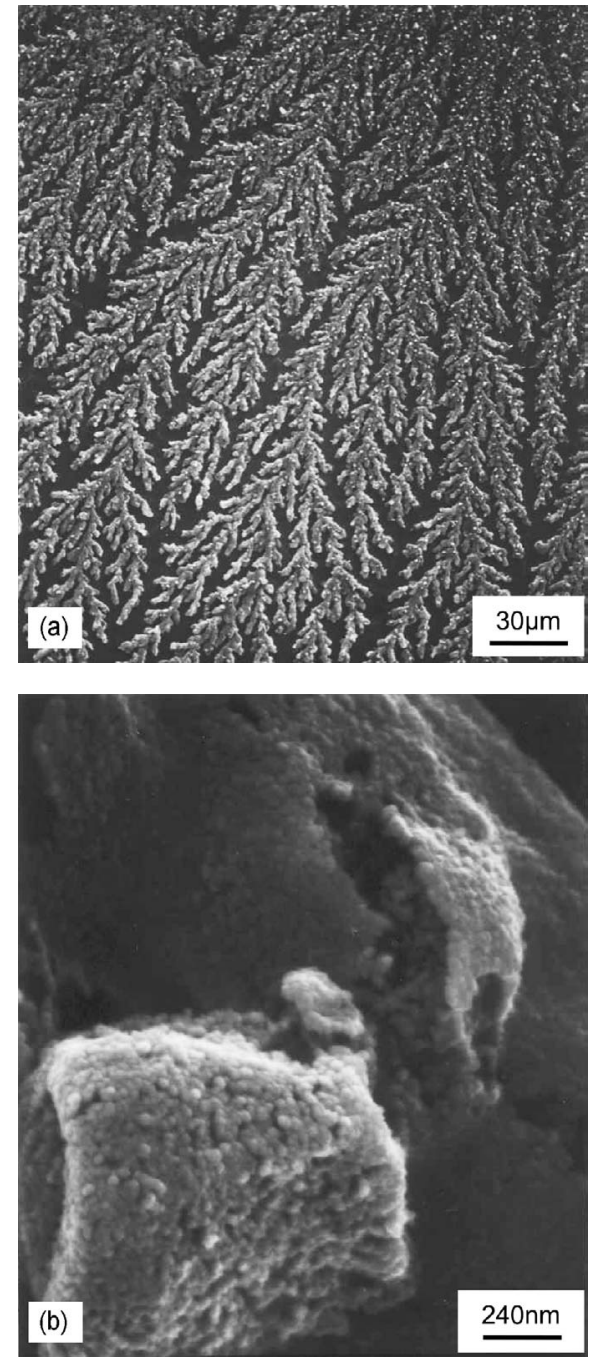

Fig. 3. SEM photographs of (a) ferrofluid prepared by the method of co-precipitation in the presence of PAA oligomer; (b) magnification of (a).

1/2, not only $\mathrm{Fe}_{3} \mathrm{O}_{4}$ but also $\mathrm{Fe}(\mathrm{OH})_{2}$ would be produced. Moreover, as shown in Eq. (5), $\mathrm{Fe}(\mathrm{OH})_{3}$ would be in excess and then converted to $\mathrm{Fe}_{2} \mathrm{O}_{3}$ if the mole concentration ratio of $\mathrm{Fe}$ (II) to $\mathrm{Fe}$ (III) were smaller than $1 / 2$ or the $\mathrm{pH}$ value were lower than 6.93 . In the reaction system we used, the mole concentrations of $\mathrm{Fe}$ (II) and $\mathrm{Fe}$ (III) were 0.1105 and $0.221 \mathrm{M}$ and the $\mathrm{pH}$ value of the ferrofluid after synthesis was 8.8. Therefore, these conditions of reaction were suitable to form $\mathrm{Fe}_{3} \mathrm{O}_{4}$ nanoparticles:

$2 \mathrm{Fe}(\mathrm{OH})_{3} \rightarrow \mathrm{Fe}_{2} \mathrm{O}_{3}+3 \mathrm{H}_{2} \mathrm{O}$.

\subsection{FTIR analysis}

Since there are a large surface-to-volume atomic ratio, high surface activity, and a large amount of dangling bonds on the nanoparticle surface, the atoms on the surface are apt to adsorb ions or molecules in solution. In the system of $\mathrm{Fe}_{3} \mathrm{O}_{4}$ nanoparticles dispersed in an alkaline solution of PAA oligomers, the exposed atoms of $\mathrm{Fe}$ on the surface of $\mathrm{Fe}_{3} \mathrm{O}_{4}$ particles would adsorb $\mathrm{OH}^{-}$and $\mathrm{COO}^{-}$groups of 


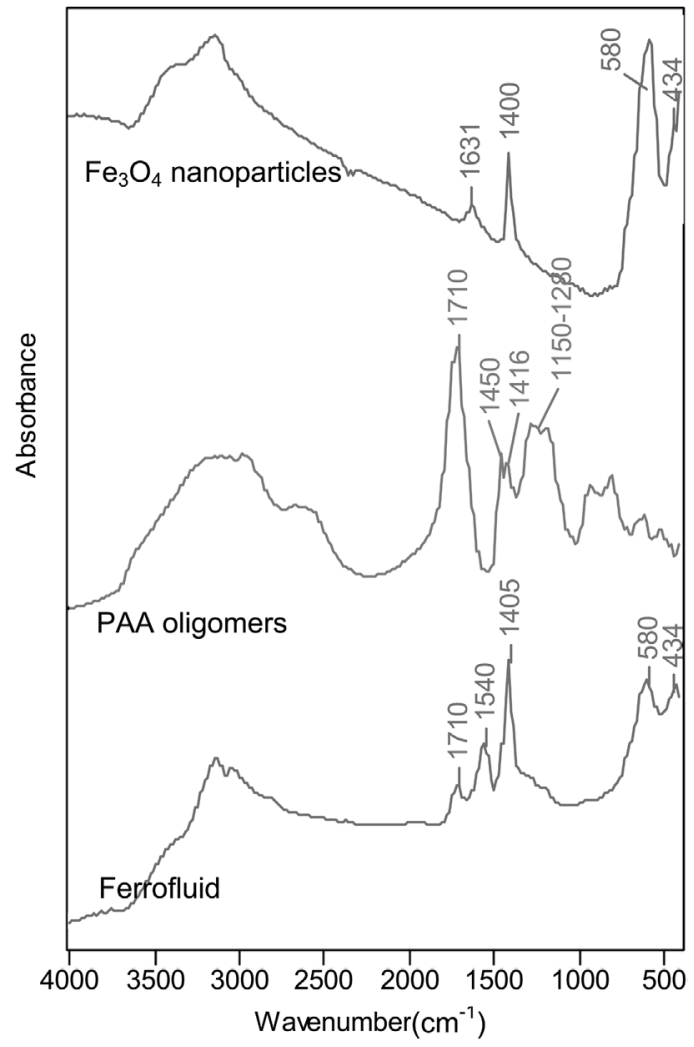

Fig. 4. FTIR analysis of $\mathrm{Fe}_{3} \mathrm{O}_{4}$ nanoparticles, PAA oligomers, and the ferrofluid prepared by the method of co-precipitation in the presence of PAA oligomers.

PAA oligomers, and the atoms of $\mathrm{O}$ on the particle surface would adsorb $\mathrm{H}^{+}$. In addition, the $\mathrm{OH}$-rich surface of $\mathrm{Fe}_{3} \mathrm{O}_{4}$ nanoparticles could also react with the residual carboxylic acid groups of PAA oligomers.

Fig. 4 shows a comparison between the FTIR spectra of the $\mathrm{Fe}_{3} \mathrm{O}_{4}$ nanoparticles, the pure PAA oligomers, and the ferrofluid prepared by co-precipitation in the presence of PAA oligomer. Previously, it was reported that the characteristic absorption bands of the $\mathrm{Fe}-\mathrm{O}$ bond of bulk $\mathrm{Fe}_{3} \mathrm{O}_{4}$ were at 570 and $375 \mathrm{~cm}^{-1}$ [27]. However, when the size of $\mathrm{Fe}_{3} \mathrm{O}_{4}$ particles was reduced to nanoscale dimensions, the surface bond force constant increased due to the effect of finite size of nanoparticles, in which the breaking of a large number of bonds for surface atoms resulted in the rearrangement of nonlocalized electrons on the particle surface [28]. Therefore, the FTIR spectrum of $\mathrm{Fe}_{3} \mathrm{O}_{4}$ nanoparticles would exhibit a blue shift and the characteristic absorption bands of the $\mathrm{Fe}-\mathrm{O}$ bond were shifted to high wavenumbers of about 580 and $434 \mathrm{~cm}^{-1}$, as shown in Fig. 4. The strong band at ca. $1710 \mathrm{~cm}^{-1}$ as shown in the FTIR spectrum of PAA oligomer is attributed to the carbonyl group stretch of the PAA oligomer [29], and the bands at ca. $1400-1450 \mathrm{~cm}^{-1}$ are attributed to the stretch of C-O and the deformation vibration of $\mathrm{OH}$ [29]. In addition, the bands at ca. $1150-1280 \mathrm{~cm}^{-1}$ are attributed to the aliphatic acid [29]. The FTIR spectrum of the ferrofluid shows that the peak at $1710 \mathrm{~cm}^{-1}$ shrank and two new peaks at ca. 1540
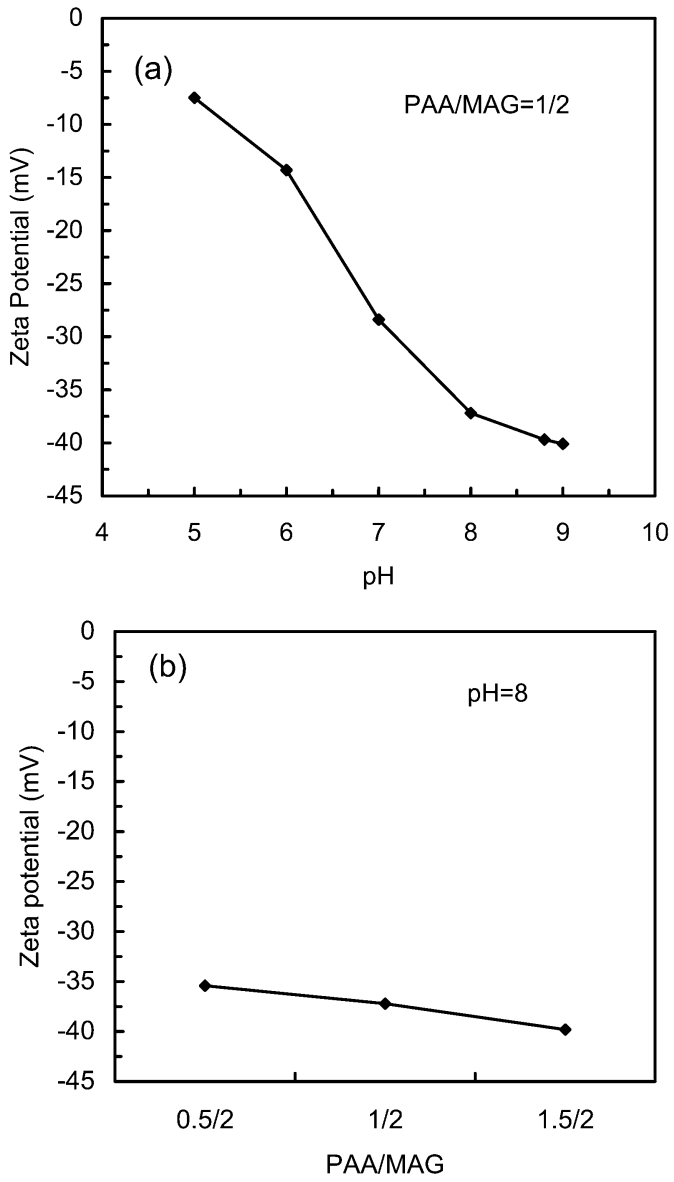

Fig. 5. The zeta potential of the ferrofluids: (a) the effect of $\mathrm{pH}$ values at constant PAA/MAG ratio; (b) the effect of PAA/MAG ratio at constant $\mathrm{pH}$ value.

and $1405 \mathrm{~cm}^{-1}$ appeared due to the binding of the carboxylic acid groups to the surface of the nanoparticles to form carboxylate groups $[30,31]$. The new peaks correspond to the $\mathrm{COO}^{-}$antisymmetric vibration and the $\mathrm{COO}^{-}$symmetric vibration, which indicate the bidentate bonding of the carbonyl groups to the surface $\mathrm{Fe}$ atoms $[32,33]$. The remaining but shrunken peak at $1710 \mathrm{~cm}^{-1}$ is due to $\mathrm{C}=\mathrm{O}$ stretch and indicates that some fraction of the PAA oligomers were bonded to nanoparticles either in monodentate form or as an acid [32,33]. Consequently, the interaction between PAA oligomers and $\mathrm{Fe}_{3} \mathrm{O}_{4}$ nanoparticles was through chemical bonding and the mechanism shown in Fig. 2 was evidenced.

\subsection{Zeta potential and light scattering analysis}

The negative zeta potential indicates that the PAA oligomers are bound to the particle surface. Fig. 5a shows the zeta potentials of sample PAA/MAG $=1 / 2$ in the solutions with different $\mathrm{pH}$ values. When the solution became more alkaline, the zeta potential became more negative that may due to the ionization of PAA oligomers. And the ionization of PAA oligomers would provide the electrostatic repulsion against the aggregation between nanoparticles. So Fig. 6a 

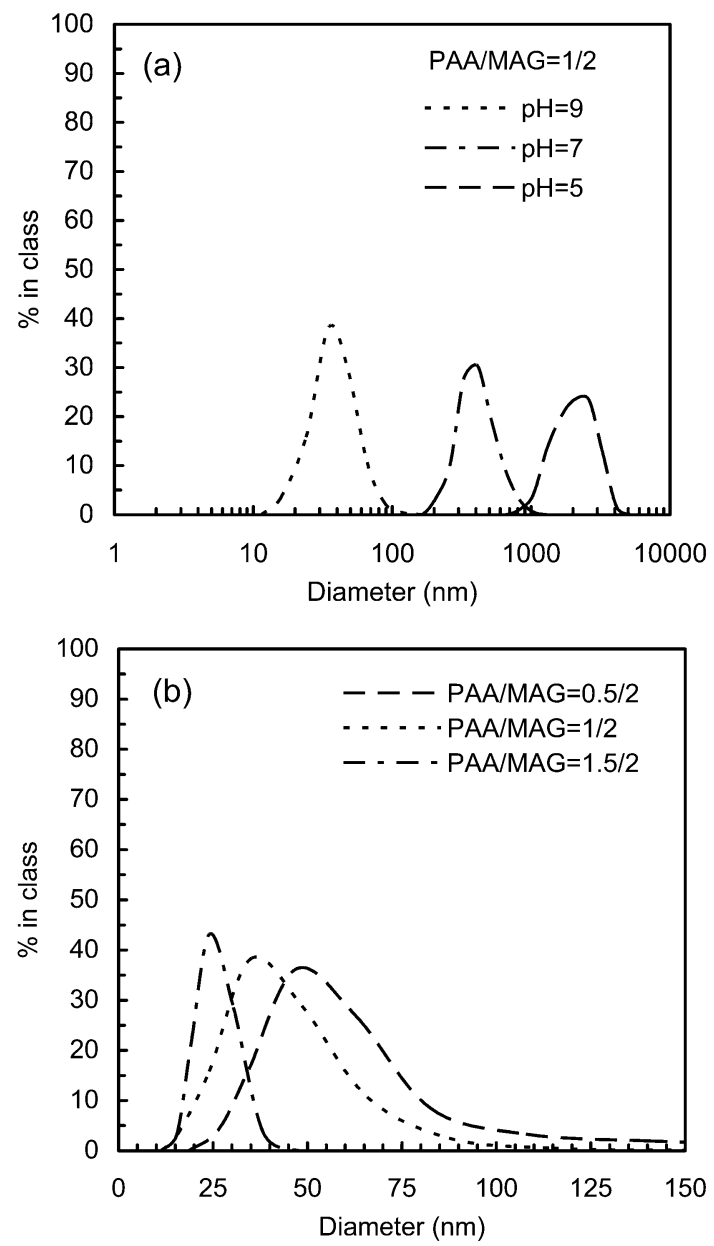

Fig. 6. The size distribution of ferrofluids (with ultrasonification before the light scattering measurement): (a) the effect of $\mathrm{pH}$ values at constant PAA/MAG ratio; (b) the effect of PAA/MAG ratio at constant $\mathrm{pH}$ value.

shows that the sample in the solution with higher $\mathrm{pH}$ value would show small and narrow size distribution.

The zeta potentials of the samples with different PAA/ MAG ratio were not changed drastically if the $\mathrm{pH}$ value of solutions were the same, as shown in Fig. 5b. But Fig. 6b shows that the sample with a higher concentration of PAA oligomer showed a small and narrow size distribution. The reason was due to the PAA oligomers that acted as templates and steric stabilizers, forming a wall to protect the particles. So the addition of the PAA oligomers in the reaction provides steric repulsion to improve the quality of the dispersion. These effects of polymeric stabilizers in metallic nanoparticle preparations were also discussed in previous studies [19-22]. Therefore, the PAA oligomers, which bonded to the surfaces of $\mathrm{Fe}_{3} \mathrm{O}_{4}$ particles, not only reduce the intrinsic particle size during their forming but also provide both factors of electrostatic and steric repulsion against the aggregation between $\mathrm{Fe}_{3} \mathrm{O}_{4}$ particles.

In addition, it is worth mentioning that when there was a high concentration of PAA oligomers in the ferrofluid, the effect of physical crosslinking due to the hydrogen bonding among $\mathrm{COOH}$ groups or the entanglement of PAA oligomers

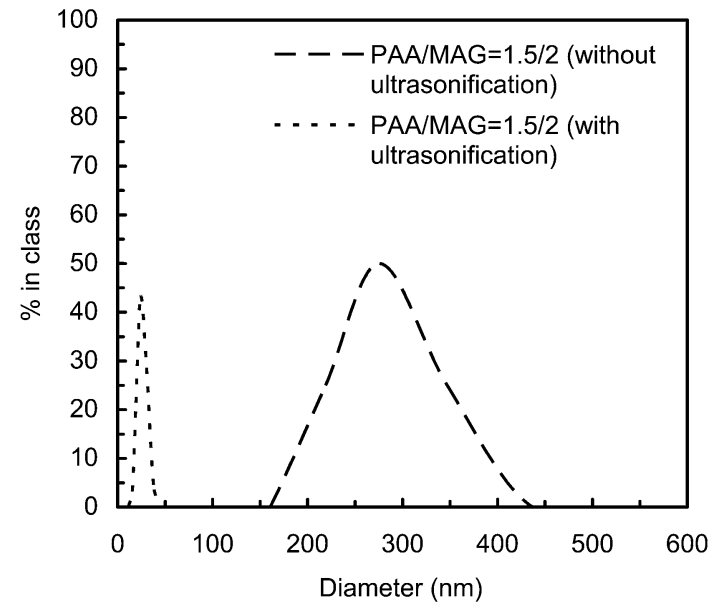

Fig. 7. Effect of ultrasonification before the light scattering measurement on the size distribution of ferrofluid

would cause a pseudo-aggregation of nanoparticles several weeks after the ferrofluid was synthesized, and therefore the size distribution of $\mathrm{Fe}_{3} \mathrm{O}_{4}$ measured by light scattering was much larger than its intrinsic size if ultrasonification was not applied before the measurement. Fig. 7 compared the size distribution of the $\mathrm{Fe}_{3} \mathrm{O}_{4}$ ferrofluid aggregates with or without ultrasonification before the light scattering measurement. It indicates that the $\mathrm{Fe}_{3} \mathrm{O}_{4}$ particles aggregated as clusters with a size range of $150-450 \mathrm{~nm}$ in the presence of high concentrations of PAA oligomers. The ultrasonification then destroyed the pseudo-aggregation in clusters and the size distribution of ferrofluid aggregates was reduced to about $10-40 \mathrm{~nm}$.

\subsection{Stability of ferrofluid}

Because the ferrofluid was stabilized by PAA oligomers, the stability of $\mathrm{Fe}_{3} \mathrm{O}_{4}$ nanoparticles in a dispersing medium could be controlled by the ionization of carboxylic acid groups of PAA oligomers. The adjustment of the $\mathrm{pH}$ value of the medium solution could control the ionization degree of PAA oligomers and thus the stability of the ferrofluid.

The $\mathrm{p} K_{a}$ value of PAA oligomers $\left(M_{\mathrm{w}} \sim 2000\right)$ could be calculated to be 4.09 by Eqs. (6) and (7). This value is close to the $\mathrm{p} K_{a}$ value of the aliphatic acid (4.0-4.5).

The concentration of carboxylic acid groups is

$C_{0}=\frac{m / M}{V}$

and

$\mathrm{p} K_{a}=-\log \left(\frac{\left(\mathrm{COO}^{-}\right)\left(\mathrm{H}^{+}\right)}{(\mathrm{COOH})}\right)=-\log \left(\frac{\left(10^{-\mathrm{pH}}\right)\left(10^{-\mathrm{pH}}\right)}{C_{0}-10^{-\mathrm{pH}}}\right)$,

in which the $\mathrm{pH}$ value of the solution was measured to be 2.43 by dissolving $1 \mathrm{~g}$ PAA oligomer $(m)$ in $80 \mathrm{~g}(\approx 80 \mathrm{~L})$ of deionic water $(V)$, and $M$ is the molecular weight of the repeating unit of the PAA oligomer $(72 \mathrm{~g} / \mathrm{mol})$. From further calculation, the relationship between the $\mathrm{pH}$ value and 


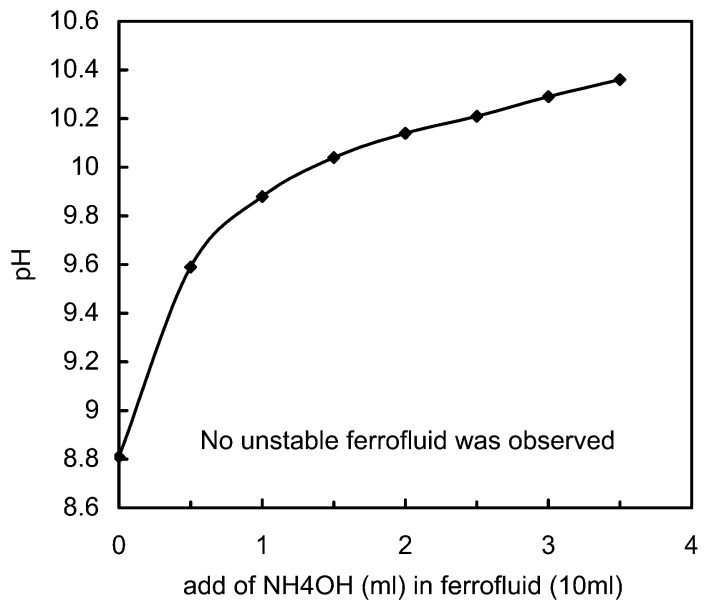

Fig. 8. The $\mathrm{pH}$ value and stability of ferrofluid observed during the process of titration by using $28 \%(\mathrm{w} / \mathrm{w})$ ammonium solution as a titrant. (The stability of the ferrofluid was observed visually after the $\mathrm{pH}$ value was stable for several minutes.)

the degree of ionization of carboxylic acid groups of PAA oligomer could be found as follows:

$\mathrm{p} K_{a}=-\log \left(\frac{C_{0}(d)\left(\mathrm{H}^{+}\right)}{C_{0}(1-d)}\right)=\mathrm{pH}-\log \left(\frac{d}{1-d}\right)$.

The symbol $d$ used here is the ionization degree of acid groups. To simplify the calculation, it was assumed that more than $99.99 \%$ of carboxylic acid groups were ionized to provide electrostatic repulsion to form the most stable ferrofluid. The $\mathrm{pH}$ value under this condition was found to be higher than 8.1. In other words, the carboxylic acid groups of PAA oligomers were almost completely ionized and the ferrofluid was stable when the $\mathrm{pH}$ value was higher than 8.1. In our experiments, after the addition of ammonium solution into the reaction system to synthesize the ferrofluid, the final $\mathrm{pH}$ value of the ferrofluid was 8.8 which assured the formation of stable ferrofluids, and the ferrofluids thus synthesized would remain stable for several months. If the ammonium solution was added continuously as shown in Fig. 8, the ferrofluid was still stable due to the acid groups being almost ionized, and not only steric repulsion but also electrostatic repulsion were provided against particle aggregation. However, Fig. 9 reveals that the $\mathrm{pH}$ value of the ferrofluid decreased gradually during the process of the titration by using methacrylic acid as a titrant. Once the $\mathrm{pH}$ value of the ferrofluid was lower than 5 , the ferrofluid became unstable within several seconds and the aggregation of particles could be observed visually. It was because the ionization degree of acid groups would be lower than $90 \%$ when the $\mathrm{pH}$ value of the ferrofluid was lower than 5 , and this condition could not provide sufficient electrostatic repulsion to preserve the stability of $\mathrm{Fe}_{3} \mathrm{O}_{4}$ nanoparticle suspension in ferrofluid. Consequently, the stability of ferrofluid could be controlled by adjusting the $\mathrm{pH}$ value of the solution, and therefore the ferrofluid could be applied properly.

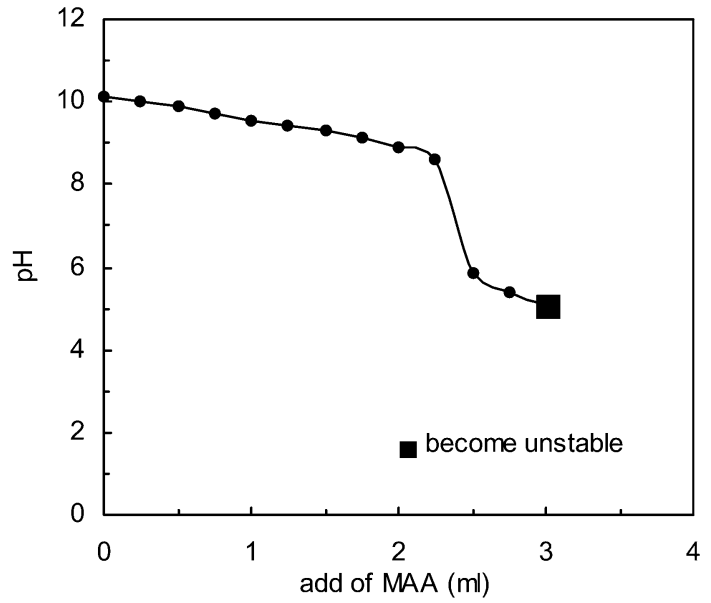

Fig. 9. The $\mathrm{pH}$ value and stability of the ferrofluid observed during the process of titration by using methacrylic acid as a titrant. (Before the process of titration, $2 \mathrm{ml} 28 \%(\mathrm{w} / \mathrm{w}$ ) ammonium solution was added into the ferrofluid. The stability of the ferrofluid was observed visually after the $\mathrm{pH}$ value was stable for several minutes.)
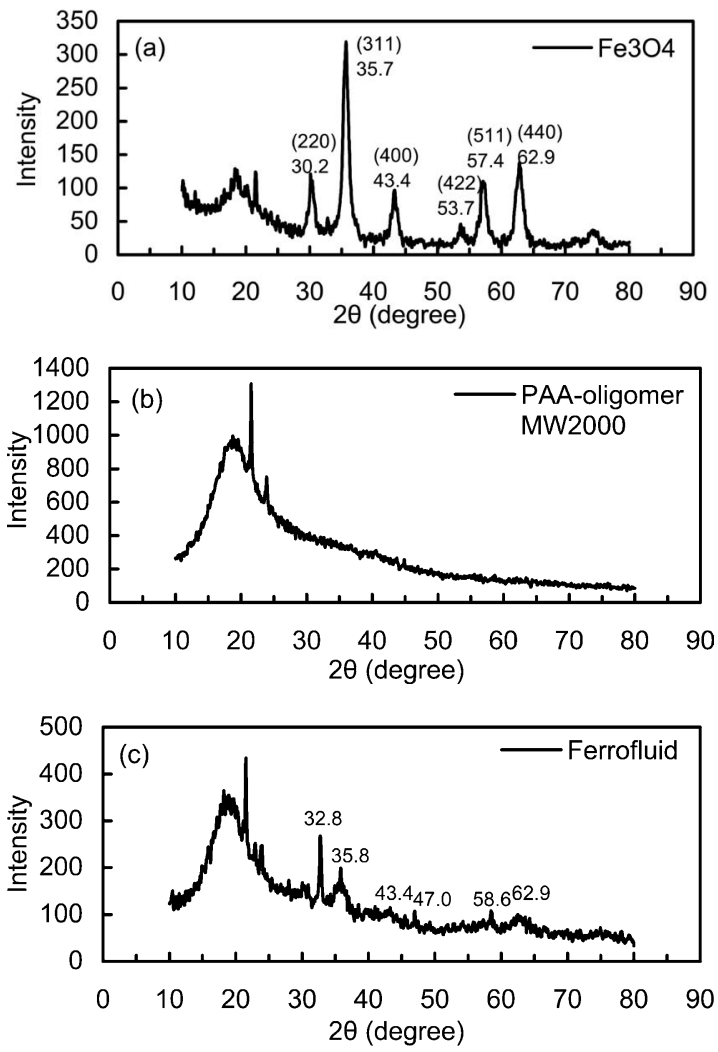

Fig. 10. XRD pattern of the pure $\mathrm{Fe}_{3} \mathrm{O}_{4}$ nanoparticles (a), PAA oligomers (b), and ferrofluid particles (c).

\subsection{XRD analysis}

To investigate the effect of PAA oligomers on the preparation of $\mathrm{Fe}_{3} \mathrm{O}_{4}$ nanoparticles, the $\mathrm{Fe}_{3} \mathrm{O}_{4}$ nanoparticles prepared in the absence of PAA oligomers and the ferrofluid prepared in the presence of PAA oligomers were analyzed by XRD and the results are shown in Fig. 10. The results show 
that the $\mathrm{Fe}_{3} \mathrm{O}_{4}$ nanoparticles prepared in the absence of PAA oligomers had six diffraction peaks at $2 \theta=30.2^{\circ}, 35.7^{\circ}$, $43.4^{\circ}, 53.7^{\circ}, 57.4^{\circ}$, and $62.9^{\circ}$, which were the characteristic peaks of standard $\mathrm{Fe}_{3} \mathrm{O}_{4}$ crystal (isometric-hexoctahedral crystal system). However, the ferrofluid prepared in the presence of PAA oligomers had an additional diffraction peak at ca. $2 \theta=32.8^{\circ}$, which was the characteristic peak of $\mathrm{Fe}_{2} \mathrm{O}_{3}$ crystal (trigonal-hexagonal scalenohedral crystal system). These results indicate that some $\mathrm{Fe}_{2} \mathrm{O}_{3}$ particles consisted in the ferrofluid because the particles were synthesized in the initial condition of low $\mathrm{pH}$ value (in PAA oligomer solution $\mathrm{pH}$ 2.43), although the $\mathrm{pH}$ value of the final ferrofluid was 8.8 after the addition of ammonium solution. At the beginning of the precipitation reaction, the acidic condition would oxidize the $\mathrm{Fe}_{3} \mathrm{O}_{4}$ or oxidize the $\mathrm{Fe}^{2+}$ to form $\mathrm{Fe}^{3+}$ partially so that an initial mole concentration ratio of $1 / 2$ in these ions would end up with excess quantities of $\mathrm{Fe}^{3+}$ and form $\mathrm{Fe}_{2} \mathrm{O}_{3}$ as mentioned in Eq. (5). In addition, the broad diffraction peaks shown in Fig. 10 indicate that the particle size of magnetite was very small according to the Debye-Scherrer equation [34,35],

$D=\frac{0.9 \lambda}{\beta \cos \theta}$,

where $D$ is the average crystallite size $(\AA), \lambda$ is the wavelength of X-rays $\left(\mathrm{Cu} K_{\alpha}: \lambda=1.5418 \AA\right), \theta$ is the Bragg diffraction angle, and $\beta$ is the full width at half maximum (FWHM) (in radians). By using Eq. (9) and the FWHM of the diffraction peak at $2 \theta=35.7^{\circ}$, the crystallite size of the $\mathrm{Fe}_{3} \mathrm{O}_{4}$ precipitated in the presence of PAA oligomer could be calculated to be $5.2 \mathrm{~nm}$, which was smaller than the crystallite size of $\mathrm{Fe}_{3} \mathrm{O}_{4}(8.3 \mathrm{~nm})$ synthesized in the absence of PAA oligomers. This result also shows that the presence of PAA oligomers reduced the particle size of $\mathrm{Fe}_{3} \mathrm{O}_{4}$ dramatically due to the fact that the carboxylic acid groups of PAA oligomers not only promoted nucleation but also inhibited growth of the $\mathrm{Fe}_{3} \mathrm{O}_{4}$ particles. Furthermore, the broad diffraction peak appeared in the range from $10^{\circ}$ to $40^{\circ}$ indicates the existence of amorphous PAA oligomers coated on the surface of $\mathrm{Fe}_{3} \mathrm{O}_{4}$ particles.

\subsection{TGA analysis}

Fig. 11 shows the TGA analysis of the pure $\mathrm{Fe}_{3} \mathrm{O}_{4}$ nanoparticles, the PAA oligomer $\left(M_{\mathrm{w}} \sim 2000\right)$, and the ferrofluid particles synthesized in the presence of PAA oligomers. The pure $\mathrm{Fe}_{3} \mathrm{O}_{4}$ nanoparticles showed insignificant weight loss from 100 to $800^{\circ} \mathrm{C}$. But there were three stages during degradation shown in the TGA curve of PAA oligomers. The initial two stages of degradation (250$300^{\circ} \mathrm{C}$ ) was due to the dehydration (Eq. (10)) [36-38] and decarboxylation (Eq. (11)) [36-38] of the carboxylic acid groups of the PAA oligomers, while the main degradation

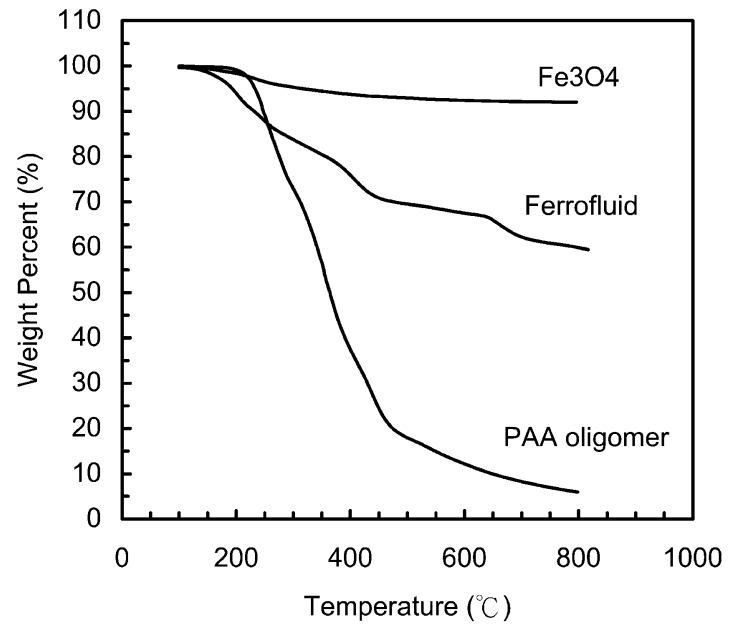

Fig. 11. TGA analysis of the pure $\mathrm{Fe}_{3} \mathrm{O}_{4}$ nanoparticles, the PAA oligomer $\left(M_{\mathrm{W}} \sim 2000\right)$, and the ferrofluid particles synthesized in the presence of PAA oligomers.

temperature of the PAA oligomer was near $400^{\circ} \mathrm{C}$ :

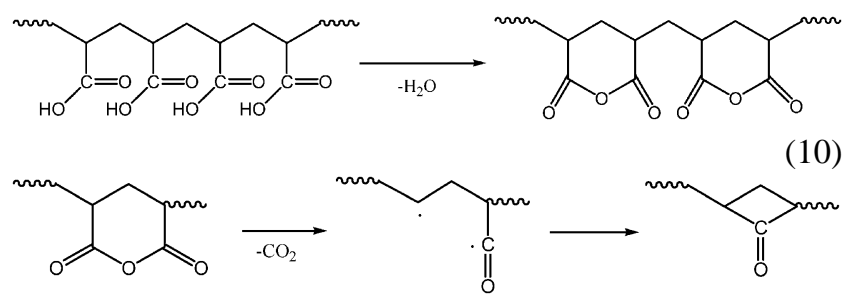

The TGA curve of ferrofluid particles also showed threestage decomposition. The first-stage decomposition, which occurred near $200^{\circ} \mathrm{C}$, was due to dehydration (Eq. (12)), which was caused by the destruction of polyelectrolyte complex between $\mathrm{COO}^{-}$and $\mathrm{NH}_{4}^{+}$and the formation of amide bondings

$\mathrm{R}-\stackrel{\mathrm{O}}{\mathrm{C}}-\mathrm{O}^{-} \mathrm{NH}_{4}^{+} \rightleftharpoons \mathrm{R}-\stackrel{\mathrm{O}}{\mathrm{C}}-\mathrm{NH}_{2}+\mathrm{H}_{2} \mathrm{O}$

Then the temperature was raised to $400{ }^{\circ} \mathrm{C}$ to enable the main degradation of PAA oligomer to occur. The interesting decomposition which occurred at $700^{\circ} \mathrm{C}$ was due to the deoxidization of the $\mathrm{Fe}_{2} \mathrm{O}_{3}$ particles, which consisted in the ferrofluid as mentioned above, to form $\mathrm{Fe}_{3} \mathrm{O}_{4}$ at $700^{\circ} \mathrm{C}$ under $\mathrm{N}_{2}$ atmosphere. Therefore, both the decomposition of PAA oligomers and the deoxidization of $\mathrm{Fe}_{2} \mathrm{O}_{3}$ contributed to the weight loss of the TGA analysis of ferrofluid particles. The residual weight percentage of ferrofluid particles after the TGA analysis (about 60\%) was mainly the contribution of the $\mathrm{Fe}_{3} \mathrm{O}_{4}$ nanoparticles and a small amount of char yield induced from PAA oligomers. The results indicate that the weight ratio of PAA oligomers $(\sim 40 \%)$ to $\mathrm{Fe}_{3} \mathrm{O}_{4}$ nanoparticles $(\sim 60 \%)$ was nearly $1: 2$, where the ferrofluid was dialyzed before the TGA measurement. Theoretically, from the feed composition the weight ratio of PAA oligomers to $\mathrm{Fe}_{3} \mathrm{O}_{4}$ nanoparticles in the ferrofluid was cal- 


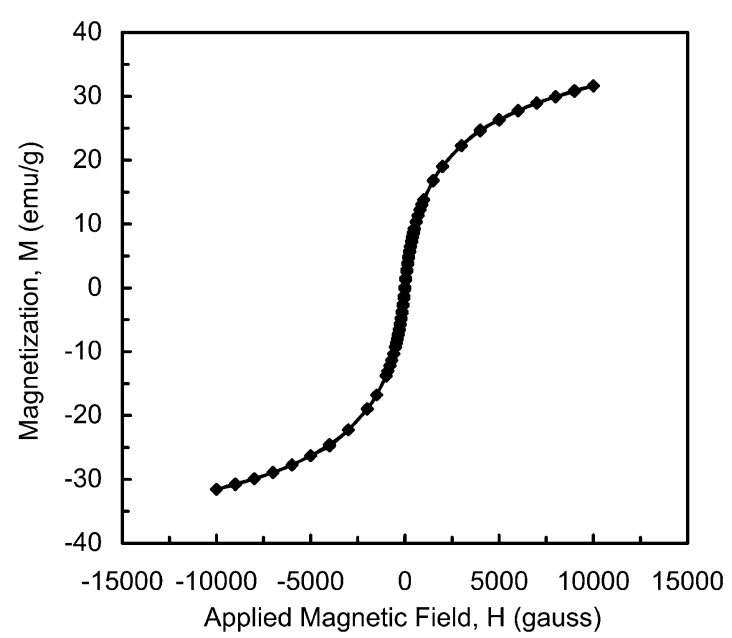

Fig. 12. SQUID magnetization curve of the ferrofluid particles synthesized in the presence of PAA oligomers.

culated to be also $1 / 2$. It could be concluded from this result that the PAA oligomers $\left(M_{\mathrm{w}} \sim 2000\right)$ were chemically bonded on the surface of the magnetite nanoparticles and could not be removed during the dialysis even though the MWCO (molecular weight cut off) of the dialytic membrane was $6000-8000$.

\subsection{Squid analysis}

It is well known that the $\mathrm{Fe}_{3} \mathrm{O}_{4}$ nanoparticles show a superparamagnetic property. But when there was a quantity of $\mathrm{Fe}_{2} \mathrm{O}_{3}$ in the ferrofluid and the PAA oligomers were chemically bonded to nanoparticles, the magnetic property of the ferrofluid particles should be examined. The result of the SQUID analysis is shown in Fig. 12. When a magnetic field was applied, the dipolar particles aligned themselves with the applied magnetic field, and resulted in a measurable magnetization. The saturation magnetization of the ferrofluid was about $35 \mathrm{emu} / \mathrm{g}$ (emu per gram of nanoparticles (iron oxides) in the ferrofluid, where the amount of nanoparticles was determined by using TGA analysis), which was lower than the saturation magnetization of pure $\mathrm{Fe}_{3} \mathrm{O}_{4}$ nanoparticles $(50 \mathrm{emu} / \mathrm{g})$, due to the fact that the saturation magnetization reduced significantly when the particle size was smaller than $10 \mathrm{~nm}$ [39]. Also, the saturation magnetization of $\mathrm{Fe}_{2} \mathrm{O}_{3}$ nanoparticles was lower than that of $\mathrm{Fe}_{3} \mathrm{O}_{4}$ nanoparticles [40]. So the saturation magnetization of nanoparticles in the ferrofluid, which consisted of a small amount of $\mathrm{Fe}_{2} \mathrm{O}_{3}$ nanoparticles, was lower than that of pure $\mathrm{Fe}_{3} \mathrm{O}_{4}$ nanoparticles. Furthermore, the remanence and coercivity were zero, and there was no magnetic hysteresis loop as shown in Fig. 12. The magnetic susceptibility and permeability were calculated to be 0.024 and 1.302 (in the applied magnetic field from 0 to $100 \mathrm{G}$ ), which reveals superparamagnetic behavior $[18,41]$. These results indicate that the magnetic nanoparticles synthesized in the presence of PAA oligomers were superparamagnetic.

\section{Conclusion}

In this work, the method of co-precipitation was used to synthesize a water-based, stable ferrofluid that contained $\mathrm{Fe}_{3} \mathrm{O}_{4}$ nanoparticles in the presence of PAA oligomers. The PAA oligomers promoted the nucleation and inhibited the growth of the magnetic iron oxide so as to produce the smaller $\mathrm{Fe}_{3} \mathrm{O}_{4}$ nanoparticles. In addition, a lot of carboxylic acid groups of PAA oligomers were bound on the surface of $\mathrm{Fe}_{3} \mathrm{O}_{4}$ nanoparticles to suspend the $\mathrm{Fe}_{3} \mathrm{O}_{4}$ particles in a fine state of dispersion. The PAA oligomers provided both electrostatic and steric repulsion against particle aggregation, and the stability of dispersions could be controlled by adjusting the $\mathrm{pH}$ value of solution. Although there were some $\mathrm{Fe}_{2} \mathrm{O}_{3}$ particles formed in the ferrofluid in the presence of PAA oligomers, the remanence and coercivity of the ferrofluid particles were zero and the magnetic hysteresis loop was not shown. It was concluded that the nanoparticles synthesized in this work were superparamagnetic.

\section{References}

[1] K. Raj, B. Moskowitz, R. Casciari, J. Magn. Magn. Mater. 149 (1995) 174-180.

[2] D.L. Lesile-Pelecky, R.D. Rieke, Chem. Mater. 8 (1996) 1770-1783.

[3] U. Hafeli, W. Schutt, J. Teller, M. Zborowski, Scientific and Clinical Applications of Magnetic, Plenum, New York, 1997.

[4] R. Weissleder, A. Bogdanov, E.A. Neuwelt, M. Papisov, Adv. Drug Deliv. Rev. 16 (1995) 321-334.

[5] A. Jordan, R. Scholz, P. Wust, H. Schirra, J. Magn. Magn. Mater. 194 (1999) 185-196.

[6] D.K. Kim, M. Mikhaylova, F.H. Wang, J. Kehr, B. Bjelke, Y. Zhang, T. Tsakalakos, M. Muhammed, Chem. Mater. 15 (2003) 4343-4351.

[7] S.E. Khalafalla, G.W. Reimers, IEEE Trans. Magn. MAG-16 (2) (1980) 178-183.

[8] B.M. Berkovsky, V.F. Medvedev, M.S. Krakov, Magnetic Fluids: Engineering Applications, Oxford Univ. Press, New York, 1993.

[9] R.E. Rosensweig, Ferrohydrodynamics, Cambridge Univ. Press, New York, 1985.

[10] Y.S. Kang, S. Risbud, J.F. Rabolt, P. Stroeve, Chem. Mater. 8 (1996) 2209-2211.

[11] R. Massart, IEEE Trans. Magn. MAG-17 (2) (1981) 1247-1248.

[12] R. Massart, E. Dubois, V. Cabuil, E. Hasmonay, J. Magn. Magn. Mater. 149 (1995) 1-5.

[13] P.C. Hiemenz, Principles of Colloid and Surface Chemistry, third ed., Dekker, New York, 1997.

[14] J.N.K. Shimoiizaka, T. Fujita, A. Kounosu, IEEE Trans. Magn. MAG16 (2) (1980) 368-371.

[15] A. Wooding, M. Kilner, D.B. Lambrick, J. Colloid Interface Sci. 144 (1991) 236-242.

[16] Y.J. Lin, L. Wang, J.G. Lin, Y.Y. Hung, W.Y. Chiu, Synth. Met. 135136 (2003) 769.

[17] P.C. Wang, W.Y. Chiu, C.F. Lee, T.H. Young, J. Polym. Sci. A Polym. Chem. 42 (2004) 5695-5705.

[18] K. Wormuth, J. Colloid Interface Sci. 241 (2001) 366-377.

[19] H. Pardoe, W. Chua-Anusorn, T.G. Pierre, J. Dobson, J. Magn. Magn. Mater. 225 (2001) 41-46.

[20] G.D. Mendenhall, Y. Geng, J. Hwang, J. Colloid Interface Sci. 184 (1996) 519-526.

[21] J. Lee, T. Isobe, M. Senna, J. Colloid Interface Sci. 177 (1996) 490494. 
[22] X.B. Ding, Z.H. Sun, G.X. Wan, Y.Y. Jiang, React. Funct. Polym. 38 (1998) 11-15.

[23] R.S. Underhill, G. Liu, Chem. Mater. 12 (2000) 2082-2091.

[24] L.A. Harris, J.D. Goff, A.Y. Carmichael, J.S. Riffle, J.J. Harburn, M. Saunders, Chem. Mater. 15 (2003) 1367-1377.

[25] H. Hirai, H. Wakabayashi, M. Komiyama, Chem. Lett. 7 (1983) $1047-$ 1050.

[26] C.W. Chen, M. Akashi, Langmuir 13 (1997) 6465-6472.

[27] R.D. Waldron, Phys. Rev. 99 (1995) 1727-1735.

[28] M. Ma, Y. Zhang, W. Yu, H.Y. Shen, H.Q. Zhang, N. Gu, Colloids Surf. A Physicochem. Eng. Aspects 212 (2003) 219-226.

[29] L.J. Bellamy, The Infra-Red Spectra of Complex Molecules, Wiley, New York, 1975.

[30] C. Rocchiccioli-Deltche, R. Franck, V. Cabuil, R. Massart, J. Chem. Res. 5 (1987) 126-127.

[31] R.G.C. Moore, S.D. Evans, T. Shen, C.E.C. Hodson, Physica E 9 (2001) 253-261.
[32] N. Shukla, C. Liu, P.M. Jones, D. Weller, J. Magn. Magn. Mater. 266 (2003) 178-184.

[33] Q. Liu, Z. Xu, Langmuir 11 (1995) 4617-4622.

[34] R. Massart, V. Cabuil, J. Chim. Phys. Phys. Chim. Biol. 84 (1987) 967-973.

[35] A. Taylor, X-Ray Metallography, Wiley, New York, 1961, p. 674.

[36] H.G. Schild, J. Polym. Sci. A Polym. Chem. 31 (1993) 2403-2405.

[37] C.A. Fyfe, M.S. McKinnon, Macromolecules 19 (1986) 19091912.

[38] I.C. McNeill, S.M.T. Sadeghi, Polym. Degrad. Stabil. 29 (1990) 233 246.

[39] M.P. Morales, M. Andres, S. Veintemillas, M.I. Montero, C.J. Serna, J. Magn. Magn. Mater. 203 (1999) 146-148.

[40] R.M. Cornell, U. Schwertmann, The Iron Oxides, Wiley-VCH, Weinheim, 1996

[41] B.D. Cullity, Introduction to Magnetic Materials, Addison-Wesley Press, London, 1972. 